\title{
The effects of emotional arousal and gender on the associative memory deficit of older adults
}

\author{
Moshe Naveh-Benjamin • Geoffrey B. Maddox • \\ Peter Jones • Susan Old • Angela Kilb
}

Published online: 15 December 2011

(C) Psychonomic Society, Inc. 2011

\begin{abstract}
In this study we assessed the potential moderating roles of stimulus type (emotionally arousing) and participants' characteristics (gender) in older adults' associative memory deficit. In two experiments, young and older participants studied lists that included neutral and emotionally arousing word pairs (positive and negative) and completed recognition tests for the words and their associations. In Experiment 1, the majority of the word pairs were composed of two nouns, whereas in Experiment 2 they were composed of adjective-noun pairs. The results extend evidence for older adults' associative deficit and suggest that older and younger adults' item memory is improved for emotionally arousing words. However, associative memory for the word pairs did not benefit (and even showed a slight decline) from emotionally arousing words, which was the case for both younger and older adults. In addition, in these experiments, gender appeared to moderate the associative deficit of older adults, with older males but not females demonstrating this deficit.
\end{abstract}

Keywords Aging - Episodic memory - Associative memory · Gender Arousal

One issue that continues to pervade aging research is the problem of fully explaining why episodic memory declines across the lifespan. It is essential to understand the nature of

M. Naveh-Benjamin $(\bowtie) \cdot$ P. Jones $\cdot$ S. Old $\cdot$ A. Kilb

McAlester Hall, Department of Psychological Sciences,

University of Missouri,

Columbia, Missouri 65211, USA

e-mail: NavehbenjaminM@missouri.edu

G. B. Maddox

Washington University in St. Louis,

St. Louis, Missouri, USA this decline in order to help older adults maintain functionality throughout their lives. Previous work has suggested a number of contributing factors to this episodic memory decline, including deficits in semantic processing, metamemory, and deliberate recollection (see Light, 1991). Other theories have suggested that episodic memory problems may be the result of global declines in functions such as processing speed (Salthouse, 1996), attentional resources (Craik, 1983, 1986), or inhibitory control (Hasher \& Zacks, 1988) that have broader consequences for cognition.

Of particular interest in the present study is the reduced ability in later adulthood to properly bind and associate items at encoding and to retrieve those associations at a later time, suggested as one potential mechanism underlying age-related episodic memory decline (e.g., Chalfonte \& Johnson, 1996; Naveh-Benjamin, 2000; Old \& Naveh-Benjamin, 2008a). The aims of the present study were to assess the effect of emotional arousal on the associative-binding deficit of older adults and to consider potential gender differences that may exist in older adults' associative memory. Each of these issues will be addressed in turn.

\section{Associative-binding deficit and episodic memory in aging}

Chalfonte and Johnson (1996) investigated memory for complex events and their individual features in young and older adults. Their results showed a disproportionate decline in the older adult group for memories involving the binding of stimulus features (a picture, its color, and its location) relative to the decline in memory for each separate feature. This finding is in line with Naveh-Benjamin's (2000) associative-deficit hypothesis, which claims that a central factor in episodic memory decline across the lifespan is the 
inability to adequately bind elements of an event at encoding and to retrieve the bound event at a later time.

Support for the associative deficit (AD) has accumulated through several studies utilizing a wide range of stimuli. First, the $\mathrm{AD}$ has been documented with both intraitem stimuli, such as single words presented in various fonts or colors, as well as interitem stimuli, such as two words paired together (Castel \& Craik, 2003; Light, Patterson, Chung, \& Healy, 2004; Naveh-Benjamin, 2000). Thus, the AD is not simply a failure to link two separate objects, but also an inability to bind together relevant features of a single object (see also face-spatial location pairs: Bastin \& Van der Linden, 2006). Naveh-Benjamin, Hussain, Guez, and BarOn (2003) have also demonstrated an AD in older adults with the use of picture pairs (Exp. 1). More importantly, the results of Naveh-Benjamin et al.'s second experiment showed that the disproportionate age-related deficit in memory for these bound pairs decreased as semantic relatedness increased between words in a pair. This suggests that as items became easier to bind - in this case, due to reliance on semantic relationships - the AD can be reduced.

The $\mathrm{AD}$ has also been found in more ecologically valid stimuli. Naveh-Benjamin, Guez, Kilb, and Reedy (2004) tested younger and older adults using face-name associations. Older adults showed a larger decline in recognition performance on the associations between names and faces than on the separate names or faces, as compared to young adults. Similar patterns of deficits were reported for personactivity pairs (Old \& Naveh-Benjamin, 2008b). Additionally, Castel (2005) extended support for an AD in older adults using numerical stimuli in a grocery list paradigm. In one experiment, participants learned two lists of groceries separately, one with prices at market value and the other with overpriced values. The participants were later asked to recall the price of each item. The results showed equivalent recall of market-value prices across age groups, but a deficit for older adults in the overpriced condition. Importantly, these results are consistent with those of Naveh-Benjamin et al. (2003), in that they suggest that the $\mathrm{AD}$ of older adults can be reduced when associations are easier to integrate (i.e., semantic relationships, schema-appropriate associations).

\section{Benefits of emotion for memory}

The first potential moderating factor in the $\mathrm{AD}$ that we investigated in the present experiments was the emotional content of the information. Previous emotion research has suggested a memory benefit for emotional items in both young and older adults (e.g., Kensinger, 2009a; Mather \& Carstensen, 2005). The socioemotional selectivity theory (Carstensen, Fung, \& Charles, 2003) suggests that there is a directed shift in advanced age to emphasize emotional meaning, which results in a reorganization of goals to align with this shift. As a result, more attention is given to positive items, which then accounts for the positivity bias seen in the item memory performance of older adults (e.g., Charles, Mather, \& Carstensen, 2003; Mikels, Larkin, Reuter-Lorenz, \& Carstensen, 2005). It is also important to note that this "positivity bias" observed in older adults may be limited to nonarousing stimuli, and that older adults remember highly arousing negative and positive words equally well (Kensinger, 2009b).

With respect to the effects of emotion on memory for associations, Doerksen and Shimamura (2001) examined young adults' memory for intraitem associations in which emotional and nonemotional words appeared in different colors (Exp. 1), as well as for interitem stimuli in which emotionally arousing and neutral, nonarousing words each appeared within different colored boxes (Exp. 2). The results showed that participants better recalled the color source for emotional than for neutral words, due to increased arousal. Additionally, research relevant to these questions has looked at age differences in the effects of emotional arousal on reality monitoring (Kensinger, O'Brien, Swanberg, Garoff-Eaton, \& Schacter, 2007c). General recognition scores showed a benefit for negative arousing items in young adults, but a benefit for positive and negative arousing items in older adults. There was also a source-monitoring benefit for negative arousing items in younger adults. In older adults, the pattern was less clear, with neither experiment showing a benefit of positive arousal on reality monitoring, and only one of the experiments showing some benefit for negative arousing words.

These studies suggest that emotionally arousing stimuli may benefit the binding of various components in young adults (at least for pictures). Since emotional arousal seems to increase item memory in older adults, it may potentially increase associative memory in this group as well. When both words in a given pair are emotionally arousing, this may lead to the encoding of more vivid details about these words (e.g., Hamann, 2001) and may potentially help relate the words to each other, relative to pairs that include neutral words (the "arousal enhances binding" hypothesis of Mather, 2007).

Alternatively, there might be a trade-off in performance between items and associations, such that memory is better for emotionally arousing than for neutral items, but this pattern is reversed for associations. One mechanism moderating such a possibility is that paying additional attention to emotionally arousing components might compete with the creation of adequate binding (as in the attentional-narrowing hypothesis [Easterbrook, 1959] or perceptual-affective trade-offs [Mandler, 1975]; see Mather, 2007), especially in older adults, who have fewer attentional resources to invest in each association (Craik, 1983, 1986). This could 
lead to a larger AD in older adults. Similarly, Mather (2007) suggested an object-based framework that distinguishes between the binding of features within the same object (e.g., a person smiling) and the binding of two different objects (e.g., two separate faces). According to this object-based framework, binding of features within an object will be enhanced by the emotional arousal of the features of the objects relative to neutral features. In contrast, the binding of different objects together - as is the case in the present experiments, which used unrelated word pairs - may be impaired (or not affected) by emotional arousal, as attention is directed toward the single words. This can interfere with the creation of associations, leading to poorer associative memory for emotionally arousing stimuli than for neutral stimuli in younger adults, and especially in older adults who possess fewer attentional resources (see also the arousal-biased competition model of Mather \& Sutherland, 2011).

Such an alternative trade-off hypothesis is supported by previous findings with young adults involving picture-location associations for high-, medium-, and low-arousal pictures; short-term memory for location was best for low-arousal, and poorest for high-arousal, pictures (Mather et al., 2006). Kensinger, Garoff-Eaton, and Schacter (2007a) also conducted a study with young adults using emotional pictures and found a trade-off, such that objects central to the picture were remembered better if they were negative, and peripheral details of the picture were remembered better if the central object was neutral. This work was extended to older adults (Kensinger, Gutchess, \& Schacter, 2007b, Exp. 1) with similar results. Additionally, Nashiro and Mather (2011) recently reported a study in which item and associative memory were tested for emotionally arousing and neutral materials in young and older adults. The results were consistent with Mather's (2007) object-based framework, such that young adults remembered emotionally arousing intraitem associations better than neutral ones. In contrast, both young and older adults remembered neutral interitem associations better than emotionally arousing ones.

Across previous studies, however, it is important to note that the associations were between emotional and neutral components (e.g., emotional pictures and spatial location, or emotional pictures and an abstract shape). Instead, associations could consist of same-valence items, such that emotionally arousing items could be bound with other emotionally arousing items (e.g., soul-smile) and neutral items could be bound with other neutral items (e.g., usualcoat). In this instance, one might not expect a trade-off in memory for emotionally arousing material, because the similar arousing natures of the items might help in relating them together. In fact, Pierce and Kensinger (2011) recently reported a study that examined these same-valence associations in young adults, and the results failed to reveal a significant effect of valence in performance for intact associations on an immediate recognition test. Although young adults did not benefit from emotionally arousing associations, associations between same-valence components (e.g., positivepositive components) might produce a benefit to associative memory for older adults because they are more semantically related, in a way similar to the findings of semantic relatedness reported by Naveh-Benjamin et al. (2003) and Castel (2005). This question is addressed in the present study.

\section{Gender differences in episodic memory}

The present study also tested whether gender moderates the $\mathrm{AD}$ of older adults. Previous studies with young and older adults suggested a benefit for women in verbal episodic memory, as well as a comparable benefit for men in the visuospatial domain (see Herlitz, Airaksinen, \& Nordstrom, 1999; Herlitz, Nilsson, \& Backman, 1997; Herlitz \& Rehnman, 2008; Lewin et al. 2001). The memory benefit for verbal materials observed in women over men was confirmed in a study by Herlitz and Yonker (2002), who tested young adult men and women in a series of tasks involving the recall and recognition of verbal material, faces, and abstract pictorial stimuli. Their results showed that, regardless of intelligence (measured by the WAIS-R), women outperformed men on memory of verbal materials and showed a slight benefit in memory for faces. Furthermore, Meinz and Salthouse (1998) conducted a metaanalysis looking at gender and age effects for a series of tasks and found that men showed larger age-related declines than did women in verbal episodic memory tests. Finally, several studies in the literature have used spatial location memory tasks, which require the binding of an item to a location. One, by Lacreuse et al. (2005), used rhesus monkeys and showed a greater age-related decline in males than in females in a spatial delayed recognition span task. Another study, by Maylor et al. (2007), using a Web-based methodology with humans, showed a steeper age-related decline in object location memory in males than in females.

With respect to gender differences in emotional episodic memory, Hamann and Canli (2004) provided a brief review of the literature and suggested that differential amygdala activation between men and women may contribute to different levels of memory performance for emotional materials. Specifically, past research has shown that performance for emotional materials was best predicted by righthemisphere amygdala activation in men and lefthemisphere amygdala activation in women (e.g., Cahill et al., 2001; Cahill, Uncapher, Kilpatrick, Alkire, \& Turner, 2004) and, in turn, that the overlap in left-lateralized activation in the amygdala and regions responsible for encoding processes may reflect greater integration of emotional 
content and episodic memory in women (Canli, Desmond, Zhao, \& Gabrieli, 2002).

Since previous research showing an age-related $\mathrm{AD}$ has not looked at the moderating role of gender, in the present experiments we tested both young and older males and females and assessed their item and associative memory. On the basis of the above-mentioned past research, we hypothesized that women would perform better than men due to the verbal and emotionally arousing materials used in the present experiments. It also might be the case that, as in the Meinz and Salthouse (1998) findings, older women could show a smaller overall age-related decline in verbal episodic memory. Finally, with respect to the AD, based on the above studies by Lacreuse et al. (2005) and Maylor et al. (2007), who looked at memory for binding, we hypothesized that smaller age-related decline in females' episodic memory would be moderated by the memory task at handthat is, that older females would show a smaller AD than older males.

In sum, there were two important aims for the present study. First, we wanted to examine the effects of emotional arousal on the $\mathrm{AD}$ of older adults. As noted earlier, one might expect the $\mathrm{AD}$ of older adults to be reduced with emotional items relative to neutral items, given that past research has indicated improved memory for emotionally arousing items relative to neutral items (Kensinger, 2009a). Alternatively, it might be that emotional arousal actually harms associative memory. Thus, one might expect no difference between the emotional arousal conditions, or even a benefit of neutral associations over emotionally arousing ones. As discussed earlier, Mather's (2007) object-based framework suggests that intraitem associations will benefit more from emotional content than will interitem associations. To address this issue, we examined the effects of emotional arousal on item and associative memory in word pairs that were not easily integrated (e.g., noun-noun pairs; Exp. 1) and in word pairs that were more easily integrated (e.g., adjective-noun pairs; Exp. 2). Additionally, past research examining emotional associations (e.g., Doerksen \& Shimamura, 2001; Nashiro \& Mather, 2011) has typically used paired emotional and neutral items. As we noted above, Pierce and Kensinger (2011) recently reported no effect of emotional arousal on memory for intact associations between words of the same valence in young adults. However, given the disproportionate deficit in associative memory for older adults, it might be that the benefit obtained in item memory among older adults (Kensinger, 2009b) could effectively reduce the AD.

The second aim of the present study was to assess gender differences in the associative deficit. Past literature had indicated that women have superior verbal memory ability as compared with men (e.g., Herlitz \& Rehnman, 2008; Meinz \& Salthouse, 1998), as well as that males suffer a larger age-related decline in tasks requiring binding (e.g., Maylor et al., 2007), but these differences had not been tested with respect to the $\mathrm{AD}$ of older adults. Thus, the $\mathrm{AD}$ may be due to a decline in the associative memory of men relative to women.

\section{Experiment 1}

Method

Participants The participants were 28 young adults (17 female, 11 male) and 27 older adults (17 female, 10 male). The young participants were undergraduate students at the University of Missouri, who participated in the experiment for course credit. The older participants were healthy, community dwelling adults screened for good physical and mental health who received monetary compensation for their participation. Table 1 presents demographic information for the younger and older adults. As can be seen, older adults had a higher education level than did young adults ( $M \mathrm{~s}=14.30$ and 13.29 years), $t(53)=2.74, p<.01$. However, within each age group, there were no significant differences in age or level of education between males and females (all $p \mathrm{~s}>.05$ ).

Design and materials Four independent variables were used in the present experiment. The between-subjects variables included age (young vs. older) and gender (male vs. female), and the within-subjects variables included test (items vs. associations) and emotional arousal (positive, neutral, or negative).

Six lists were created that consisted of 39 word pairs each. For each list, one-third of the word pairs were positive, one-third were neutral, and one-third were negative. Each pair consisted of two words of the same emotional valence (e.g., positive [soul-smile], neutral [limb-pencil], and negative [shame-hunger]). Of these words, $80 \%$ were nouns, $10 \%$ were adjectives, and $10 \%$ were verbs. Most of the word pairs consisted of words from the same part of speech.

The stimuli in the different emotional arousal conditions were controlled for length and HAL frequency (Balota et al., 2007), as well as for imageability, meaningfulness, concreteness, and part of speech (Toglia \& Battig, 1978). Because the valence and arousal ratings reported in the Affective Norms for English Words database (Bradley \& Lang, 1999) are categorized by gender but not by age group, valence and arousal ratings were collected independently (from 12 young and 12 older adults). Valence and arousal ratings were significantly different across the different groups of emotionally arousing words $(p s<.001)$. The valence ratings were similar across males and females $(p>$ .15). However, there was a significant Age $\times$ Emotion 
Table 1 Means and standard deviations (SDs, in parentheses) of the numbers of years of formal education and ages of males and females in the younger and older adult groups in Experiments 1 and 2

\begin{tabular}{|c|c|c|c|c|c|}
\hline & & \multicolumn{2}{|l|}{ Younger } & \multicolumn{2}{|l|}{ Older } \\
\hline & & $\begin{array}{l}\text { Males }(n=11 ; 21) \\
M(S D)\end{array}$ & $\begin{array}{l}\text { Females }(n=18 ; 18) \\
M(S D)\end{array}$ & $\begin{array}{l}\text { Males }(n=10 ; 19) \\
M(S D)\end{array}$ & $\begin{array}{l}\text { Females }(n=17 ; 18) \\
M(S D)\end{array}$ \\
\hline \multirow[t]{2}{*}{ Exp. 1} & Age & $18.9(0.83)$ & $18.7(2.36)$ & $73.4(6.61)$ & $74.3(5.66)$ \\
\hline & Education & $13.27(0.19)$ & $13.29(0.77)$ & $15.10(0.16)$ & $13.82(0.13)$ \\
\hline \multirow[t]{2}{*}{ Exp. 2} & Age & $19.0(1.03)$ & $18.6(0.64)$ & $70.6(3.96)$ & $72.2(4.30)$ \\
\hline & Education & $13.29(0.98)$ & $13.35(0.50)$ & $15.31(1.49)$ & $15.23(1.30)$ \\
\hline
\end{tabular}

The $n$ s are reported for each gender and age group in Experiments 1 and 2, respectively.

interaction, $F(2,176)=37.62, p<.001$, which reflected negative and positive ratings that were closer to the neutral point of the scale for older adults as compared with younger adults. Essential for the present study was that no differences appeared in arousal ratings as a function of age or gender (all $p \mathrm{~s}>.15$ ).

In addition, word pairs were chosen so that the two items were unrelated. This was based on an independent sample of young participants who rated each word pair on the basis of associative strength. The pairing was done in such a way that no differences occurred in relatedness judgments between the different emotional arousal conditions, with an overall mean rating of 3.18 on a $1-10$ scale ( 1 being least related). The order of list presentation was counterbalanced across participants, with the order of word pairs within a list randomly determined.

Procedure Prior to the experimental phase, all participants completed a practice session consisting of one short practice list that included all three emotional arousal conditions, followed by item and associative recognition tests. For the experimental phase, participants were tested individually and presented with six study-test blocks. To provide favorable encoding conditions for the older adults, the rate of presentation was relatively slow, with word pairs presented on a computer screen one at a time for $6 \mathrm{~s}$ per pair in both age groups. Participants were instructed to learn the individual words as well as the association in preparation for the item and associative recognition tests, whose nature was explained.

After the encoding phase, participants completed an interpolated activity of counting backward by $3 \mathrm{~s}$ for $30 \mathrm{~s}$, and then proceeded with the item and associative recognition tests. The order of the tests was counterbalanced across participants. Additionally, word pairs were counterbalanced across test types (i.e., item test, intact associations, recombined associations).

As can be seen in Table 2, the item recognition test for each list consisted of 30 words (10 from each of the three emotional arousal conditions). Half of the items within each of the arousal conditions were previously studied items, and half were unstudied items. Unstudied items were selected from the same databases used to create the study lists. Participants were instructed to say "yes" if a word had appeared in the study phase and "no" if it had not. The associative test consisted of 30 word pairs (10 from each of the three emotional arousal conditions). Participants were told that all of the words had been previously studied and that they were to say "yes" if the word pair was intact (i.e., both words had been previously studied together) and "no"

Table 2 Examples of the item and association test construction in Experiments 1 and 2

\begin{tabular}{|c|c|c|c|c|c|c|c|c|}
\hline & \multirow[b]{2}{*}{ Valence } & \multirow[b]{2}{*}{ Study List } & \multicolumn{3}{|l|}{ Item Test } & \multicolumn{3}{|c|}{ Association Test } \\
\hline & & & Targets & Distractors & Total & Intact & Recombined & Total \\
\hline \multirow[t]{4}{*}{ Experiment 1} & Positive & Pairs $1-13$ & 5 items (Pairs 1-3) & 5 items & 10 items & Pairs $4-8$ & Pairs 9-13 & 10 pairs \\
\hline & Neutral & Pairs 14-26 & 5 items (Pairs 14-16) & 5 items & 10 items & Pairs $17-21$ & Pairs 22-26 & 10 pairs \\
\hline & Negative & Pairs 27-39 & 5 items (Pairs 27-29) & 5 items & 10 items & Pairs 30-34 & Pairs 35-39 & 10 pairs \\
\hline & & & & & 30 items & & & 30 pairs \\
\hline \multirow[t]{5}{*}{ Experiment 2} & $\mathrm{~N}-\mathrm{N}$ & Pairs $1-10$ & 8 items (Pairs 1-4) & 8 items & 16 items & Pairs $5-7$ & Pairs $8-10$ & 6 pairs \\
\hline & $\mathrm{N}-\mathrm{V}$ & Pairs $11-20$ & 8 items (Pairs 11-14) & 8 items & 16 items & Pairs $15-17$ & Pairs 18-20 & 6 pairs \\
\hline & $\mathrm{V}-\mathrm{N}$ & Pairs $21-30$ & 8 items (Pairs 21-24) & 8 items & 16 items & Pairs 25-27 & Pairs 28-30 & 6 pairs \\
\hline & $\mathrm{V}-\mathrm{V}$ & Pairs $31-40$ & 8 items (Pairs 31-34) & 8 items & 16 items & Pairs $35-37$ & Pairs $38-40$ & 6 pairs \\
\hline & & & & & 64 items & & & 24 pairs \\
\hline
\end{tabular}


if the word pair was rearranged (i.e., if the left and right words were recombined). For all pairs, the words appeared in their original positions (either left or right position within the pair) and were paired with a word in the same emotional arousal condition. Again, participants completed this procedure for six separate lists to ensure a sufficient number of observations across arousal conditions and test types. This yielded a total of 30 studied items and 30 distractors for each arousal condition in the item test and 30 intact and 30 recombined pairs in each arousal condition in the associative test. Words that appeared in the item test did not appear in the association test, and vice versa.

Results

Overall accuracy Results were collapsed across all six lists, because a preliminary analysis indicated no interaction between order and any of the other independent variables. For each participant, a corrected recognition score was calculated by subtracting the proportion of false alarms from the proportion of hits. These scores were used for all subsequent analyses, since generally similar patterns were found when hits and false alarms were analyzed separately (see the following).

Table 3 shows proportions of hits minus proportions of false alarms (with $S D$ s in parentheses) for the different combinations of conditions for younger and older adults. The data were first submitted to a 2 (age) $\times 2$ (gender) $\times 2$ (test) $\times 3$ (emotional arousal) mixed-factor ANOVA. The results revealed a significant main effect of test, in which performance was better in the item test than in the associative test $(M \mathrm{~s}=.53$ and .45 , respectively), $F(1,51)=12.45, M S E=$ $.035, p<.01, \eta_{\mathrm{p}}{ }^{2}=.19$, and a significant effect of gender, in which women performed better than men $(M \mathrm{~s}=.54$ and .44 , respectively), $F(1,51)=4.51, M S E=.161, p<.05, \eta_{\mathrm{p}}{ }^{2}=.08$.
As can be seen in Table 3, there was a significant interaction between age and test, $F(1,51)=4.05, M S E=.035, p<$ $.05, \eta_{\mathrm{p}}{ }^{2}=.07$, extending support for the $\mathrm{AD}$ with aging. Follow-up comparisons showed no significant difference between young $(M=.54)$ and older $(M=.52)$ adults in item test performance, $t(53)=0.52$, n.s., but significantly better performance for young adults $(M=.51)$ than older adults $(M=.40)$ in the association test, $t(53)=1.96, p=.05$. Furthermore, the two-way interaction between age and test was qualified by a significant three-way interaction between age, test, and gen$\operatorname{der}, F(1,51)=4.00, M S E=.035, p=.05, \eta_{\mathrm{p}}{ }^{2}=.07$. Figure 1 shows that there was a strong pattern of interaction between age and test for males but not for females. Follow-up analyses for males using a 2 (test) $\times 2$ (age) ANOVA, collapsed across emotional arousal, revealed a main effect of age, in which young males performed better than older males, $F(1,51)=$ 4.53, $M S E=.035, p<.05$, and, more importantly, a significant interaction between test and age, $F(1,51)=6.50, M S E=$ $.035, p<.05$. This interaction was due to the decrease in associative memory in older males relative to young males, $t(19)=2.72, p<.05$, but no differences between the two groups in the item test performance, $t(19)=$ 0.95 , n.s. In contrast, older females showed performance similar to that of younger females in both tests, with no indication of an Age $\times$ Test interaction in this group, $F$ $(1,51)=0.001, M S E=.035$, n.s.

Finally, although the effect of emotional arousal was not significant, $F(2,102)<1$, n.s., test and emotional arousal interacted significantly, $F(2,102)=4.79, M S E=.022, p<$ $.05, \eta_{\mathrm{p}}{ }^{2}=.08$, as can be seen in Fig. 2. Pairwise comparisons revealed significantly higher performance in the item test for positive $(M=.56)$ and negative $(M=.57)$ arousing words, as compared to neutral, nonarousing words $(M=.48)$, all $p s<.05$. These comparisons also revealed slightly lower performance in the associative test for positive $(M=.46)$ and negative $(M=$ .46) arousing words than for neutral, nonarousing words ( $M=$ .48 ), although these differences were not significant, $p>.10$.

Table 3 Mean proportions of hits minus false alarms (with $S D$ s in parentheses) for the different combinations of emotional arousal conditions and gender for younger and older adults in Experiment 1

\begin{tabular}{|c|c|c|c|c|c|c|c|c|}
\hline & & & \multicolumn{3}{|l|}{ Item } & \multicolumn{3}{|c|}{ Associative } \\
\hline & & & Positive & Neutral & Negative & Positive & Neutral & Negative \\
\hline \multirow[t]{4}{*}{ Young } & Male & $M$ & .51 & .45 & .60 & .50 & .56 & .50 \\
\hline & & $S D$ & $(.28)$ & $(.25)$ & $(.23)$ & $(.25)$ & $(.26)$ & $(.24)$ \\
\hline & Female & $M$ & .63 & .53 & .54 & .48 & .50 & .50 \\
\hline & & $S D$ & $(.17)$ & $(.22)$ & $(.25)$ & $(.23)$ & $(.29)$ & $(.25)$ \\
\hline \multirow[t]{4}{*}{ Old } & Male & $M$ & .46 & .39 & .50 & .26 & .28 & .30 \\
\hline & & $S D$ & $(.17)$ & $(.16)$ & $(.13)$ & $(.21)$ & $(.23)$ & $(.25)$ \\
\hline & Female & $M$ & .60 & .52 & .63 & .53 & .53 & .48 \\
\hline & & $S D$ & $(.20)$ & $(.15)$ & $(.14)$ & $(.21)$ & (.19) & $(.18)$ \\
\hline
\end{tabular}




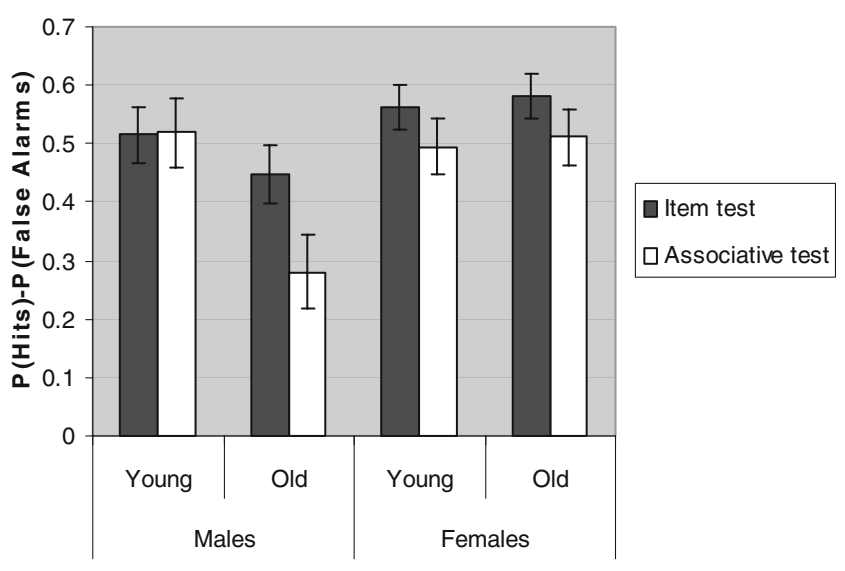

Fig. 1 Memory performance (mean proportions of hits minus proportions of false alarms) as a function of age group, gender, and test type (with standard errors) in Experiment 1

This interaction pattern was similar in younger and older adults (see Table 3).

Separate proportions of hits and false alarms Table 4 shows proportions of hits and false alarms (with $S D$ s in parentheses) for the different combinations of conditions for younger and older adults. Appendix A presents the ANOVAs conducted for the separate hits and false alarms, which were generally in line with the results for the hits-minus-falsealarms measure reported above.

\section{Discussion}

There are three important findings from Experiment 1 for overall accuracy. First, our results extend evidence for the AD of older adults (e.g., Naveh-Benjamin, 2000), as this group showed a greater difference between the overall accuracies for item and associative memory $(M=.12)$ than did

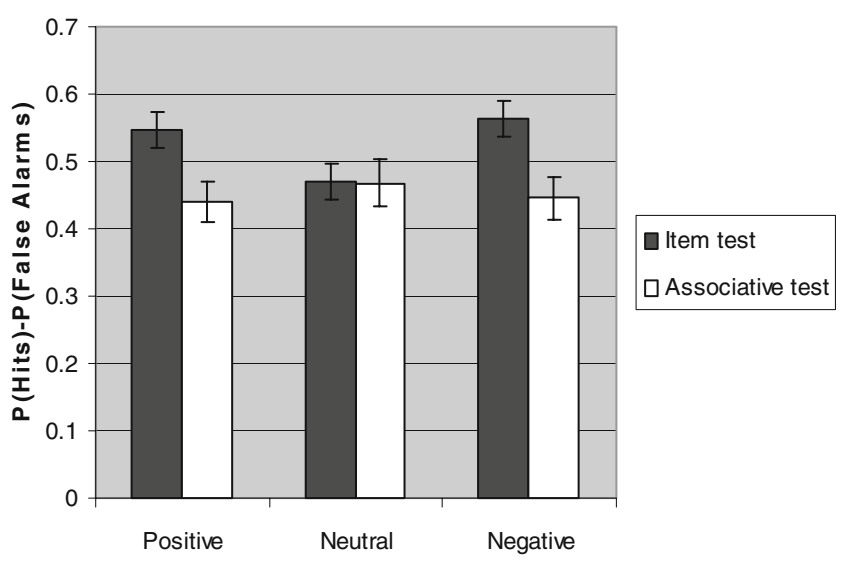

Fig. 2 Memory performance (mean proportions of hits minus proportions of false alarms) as a function of emotional arousal and test type (with standard errors) in Experiment 1 young adults $(M=.03)$. Second, older males but not females showed an $\mathrm{AD}$ relative to the comparable young adult groups. Specifically, women showed no difference in item or associative memory performance across age groups, whereas older men performed significantly lower on the associative (relative to the item) memory test than did young men $\left(M_{\text {diff }}=.17\right.$ for overall accuracy). Third, item memory increased for positive and negative arousing words across age groups, which is consistent with previous studies (e.g., Kensinger, 2009b; Mather \& Carstensen, 2005). However, emotionally arousing words did not help (and even somewhat disrupted) memory for the associations relative to neutral words, and this was the case in both age groups. This pattern of results replicates findings reported by Pierce and Kensinger (2011) for young adults and extends them to older adults. However, it might be the case that increasing the ease with which items in a given pair are integrated may produce a benefit for emotional associations over neutral associations. This possibility was examined in Experiment 2.

\section{Experiment 2}

The results from Experiment 1 were inconsistent with both predictions regarding the effects of emotional arousal on associative memory. Given that there were no differences in performance on the associative memory test across the three emotional arousal conditions in either age group, it might be that emotional arousal benefits associative memory, but only when the items can be easily integrated. As we discussed in the introduction, the $\mathrm{AD}$ has been reduced with interitem associations when the semantic relatedness of the two items was increased (Naveh-Benjamin et al., 2003), which may also suggest that the ease with which the two components are integrated will influence the size of the AD. In other words, the degree to which items can be integrated into cohesive representations may influence the benefit of emotional associations. In Experiment 1, most word pairs consisted of two nouns (e.g., soul-smile), which might not be as easily integrated as other combinations of parts of speech. This possibility is examined in Experiment 2 through the use of adjective-noun pairs, which might facilitate the creation of stronger associations through more integrated linguistic representations (e.g., deep-box, regularchair). We predict that more easily integrated pairs of emotionally arousing words will benefit associative memory performance over neutral pairs. However, as discussed in the introduction, it may be the case that emotional interitem associations will produce lower associative performance relative to neutral interitem associations, due to the additional attention paid to each of the emotional components.

Additionally, we examined both same-valence and mixed-valence word pairs in Experiment 2. This allowed 
Table 4 Mean proportions of hits (top) and false alarms (bottom; SDs in parentheses throughout table) for the different combinations of emotional arousal conditions and gender for the younger and older adults in Experiment 1

\begin{tabular}{|c|c|c|c|c|c|c|c|c|}
\hline & & & \multicolumn{3}{|l|}{ Item } & \multicolumn{3}{|c|}{ Associative } \\
\hline & & & Positive & Neutral & Negative & Positive & Neutral & Negative \\
\hline \multicolumn{9}{|l|}{ Hits } \\
\hline \multirow[t]{4}{*}{ Young } & Male & $M$ & .68 & .60 & .71 & .67 & .71 & .72 \\
\hline & & $S D$ & $(.17)$ & (.17) & $(.17)$ & $(.17)$ & $(.20)$ & (.17) \\
\hline & Female & $M$ & .78 & .67 & .71 & .69 & .64 & .69 \\
\hline & & $S D$ & $(.16)$ & (.16) & $(.16)$ & $(.16)$ & $(.21)$ & $(.16)$ \\
\hline \multirow[t]{4}{*}{ Older } & Male & $M$ & .78 & .69 & .76 & .67 & .61 & .75 \\
\hline & & $S D$ & $(.16)$ & (.16) & $(.16)$ & (.19) & $(.19)$ & $(.16)$ \\
\hline & Female & $M$ & .80 & .62 & .79 & .73 & .69 & .74 \\
\hline & & $S D$ & $(.16)$ & $(.16)$ & $(.16)$ & $(.16)$ & $(.21)$ & $(.16)$ \\
\hline \multicolumn{9}{|c|}{ False Alarms } \\
\hline \multirow[t]{4}{*}{ Young } & Male & $M$ & .17 & .15 & .12 & .17 & .15 & .22 \\
\hline & & $S D$ & (.13) & (.13) & $(.13)$ & $(.13)$ & $(.13)$ & $(.17)$ \\
\hline & Female & $M$ & .16 & .14 & .18 & .21 & .14 & .19 \\
\hline & & $S D$ & $(.12)$ & $(.12)$ & $(.12)$ & $(.12)$ & $(.12)$ & $(.12)$ \\
\hline \multirow[t]{4}{*}{ Older } & Male & $M$ & .32 & .30 & .27 & .41 & .33 & .44 \\
\hline & & $S D$ & (.13) & (.13) & $(.13)$ & $(.13)$ & $(.13)$ & (.13) \\
\hline & Female & $M$ & .20 & .11 & .16 & .20 & .16 & .26 \\
\hline & & $S D$ & (.12) & (.12) & $(.12)$ & $(.12)$ & $(.12)$ & (.12) \\
\hline
\end{tabular}

us to assess how the degree of same-valence arousal within word pairs influenced item and associative memory in young and older adults, and also allowed for a comparison of the two extreme conditions (N-N [neutral-neutral] vs. V$\mathrm{V}$ [valenced-valenced]) with respect to their effects on item and associative memory. A trade-off has often been reported when mixed-valence associations are examined, such that item memory is better for emotionally arousing material, but associative memory is better for neutral material (e.g., Mather \& Nesmith, 2008); however, no difference across valence conditions was observed in young adult associative memory when same-valence associations were tested (e.g., negative-negative word pairs; Pierce \& Kensinger, 2011).

Finally, Experiment 1 revealed an AD for older men but not women, and interestingly, there was no difference in performance across young and older women on the item and associative tests. Thus, we wanted to replicate these findings in a second experiment with a different sample of participants.

\section{Method}

Participants A total of 39 young adults (18 female, 21 male) and 37 older adults (18 female, 19 male), drawn from the same pool as in Experiment 1, participated in this experiment. None had participated in Experiment 1. As in Experiment 1, the older adults had a higher level of formal education than did the young adults $(M \mathrm{~s}=13.41$ and
15.35 years for the young and older adults, respectively), $t$ $(74)=6.33, p<.01$. However, within each age group, there were no significant differences in age and level of education between males and females (see Table 1).

Design and materials Four independent variables were used in the present experiment. The between-subjects variables included age (young vs. older) and gender (male vs. female), and the within-subjects variables included test (items vs. associations) and emotional arousal (four combinations of emotionally arousing and neutral adjective-noun pairs: $\mathrm{N}-$ $\mathrm{N}, \mathrm{V}-\mathrm{N}, \mathrm{N}-\mathrm{V}$, and $\mathrm{V}-\mathrm{V})$.

Three lists were created that consisted of 40 word pairs each: $10 \mathrm{~N}-\mathrm{N}$ (e.g., usual-coat), $10 \mathrm{~N}-\mathrm{V}$ (e.g., entiretomb), $10 \mathrm{~V}-\mathrm{N}$ (e.g., corrupt-fact), and $10 \mathrm{~V}-\mathrm{V}$ (e.g., cheerful-fantasy). Half of the emotionally arousing words were positive and half were negative, with the words within a pair in the $\mathrm{V}-\mathrm{V}$ condition being of the same valence, either both positive or both negative, as a way of increasing the ease of integration and association.

The stimuli were taken from the same sources as in Experiment 1. To ensure that the word pairs in the different conditions did not differ with respect to the perceived relatedness among the pairs, we asked a different group of participants to rate each word pair regarding whether the two words were related to each other in terms of their meanings, on a scale from 1 to 10 . The results showed no 
significant differences among the four emotional arousal conditions, with an overall mean rating of 2.8 , which indicates that the words in each pair were perceived as being quite unrelated with respect to their individual meanings. With respect to the semantic cohesiveness of each pair, the pairs in the four conditions received similar "making sense together" ratings, with an overall mean rating of 5.2 on a 10point scale, with 1 indicating not making sense at all together and 10 indicating making a lot of sense together.

Procedure The procedures for the encoding and interpolated activity phases with each of the three lists were identical to those used in Experiment 1. As can be seen in Table 2, the item recognition test for each list consisted of 64 words, with equal representation from each of the four emotional arousal combinations as well as equal representations of nouns and adjectives. Half of the test items had appeared in the study list (targets), and half were new (distractors) with the same emotional arousal distribution as the targets. Participants were instructed to say "yes" if a word had appeared in the study phase or "no" if it had not. The associative test consisted of 24 word pairs, all of which comprised words studied during the encoding phase. Again, one-fourth of the word pairs were from each of the four emotional arousal combinations. In this test, half of the word pairs from each emotional arousal condition were presented as they had been at study (intact), and half were recombined. As in Experiment 1, participants were instructed to say "yes" if the word pair was intact, meaning that both words had been presented together during the encoding phase, and "no" if the word pair was recombined. Across lists, participants were tested on 24 studied items and 24 distractor items, as well as on 9 intact and 9 recombined pairs, in each emotional arousal condition.
Results

Overall accuracy As in Experiment 1, for each participant, a corrected recognition score was calculated by subtracting the proportion of false alarms from the proportion of hits. Since there were no differences in performance between the positively and negatively valenced information, we averaged performance over positive and negative arousing words for each valence condition.

Table 5 shows proportions of hits minus proportions of false alarms (with $S D$ s in parentheses) for the different combinations of conditions for younger and older adults (we collapsed across all order conditions, as a preliminary analysis indicated no interaction of list order with any of the independent variables). The data were first submitted to a 2 (age) $\times 2$ (gender) $\times 2$ (test) $\times 4$ (emotional arousal) mixedfactor ANOVA. The results revealed a marginally significant main effect of age, in which the performance of younger adults $(M=.51)$ was higher than that of older adults $(M=.45), F(1,72)=2.96, M S E=.229, p<.10, \eta_{\mathrm{p}}^{2}=.04$. The effect of emotional arousal was also significant, $F(3$, 216) $=20.49, M S E=.039, p<.01, \eta_{\mathrm{p}}^{2}=.22$. Follow-up comparisons showed that the two combinations $\mathrm{V}-\mathrm{N}(M=$ $.55)$ and $\mathrm{V}-\mathrm{V}(M=.51)$ were remembered significantly better than $\mathrm{N}-\mathrm{N}(M=.43)$ and $\mathrm{N}-\mathrm{V}(M=.42), t(74)=$ $7.73, p<.01$. Likewise, comparison of the two extreme conditions (N-N vs. V-V) showed overall better performance for the emotionally arousing adjective-noun pairs $(M=.51)$ over the neutral adjective-noun pairs $(M=.43)$, $t(74)=3.93, p<.01$. Interestingly, the comparison of the two mixed-valence conditions $(\mathrm{N}-\mathrm{V}$ and $\mathrm{V}-\mathrm{N})$ showed a clear advantage of the latter $(M \mathrm{~s}=.55$ and .42 for $\mathrm{V}-\mathrm{N}$ and $\mathrm{N}-\mathrm{V}$, respectively), $t(74)=4.17, p<.01$. This pattern was similar for both tests.

Table 5 Mean proportions of hits minus false alarms (with $S D$ s in parentheses) for the different combinations of emotional arousal conditions and gender for the younger and older adults in Experiment 2

\begin{tabular}{|c|c|c|c|c|c|c|c|c|c|}
\hline & & \multicolumn{4}{|l|}{ Item } & \multicolumn{4}{|c|}{ Associative } \\
\hline & & $\mathrm{N}-\mathrm{N}$ & $\mathrm{N}-\mathrm{V}$ & $\mathrm{V}-\mathrm{N}$ & $\mathrm{V}-\mathrm{V}$ & $\mathrm{N}-\mathrm{N}$ & $\mathrm{N}-\mathrm{V}$ & $\mathrm{V}-\mathrm{N}$ & $\mathrm{V}-\mathrm{V}$ \\
\hline \multicolumn{10}{|l|}{ Young } \\
\hline \multirow[t]{2}{*}{ Male } & $M$ & .45 & .54 & .60 & .61 & .51 & .52 & .63 & .57 \\
\hline & $S D$ & $(.23)$ & (.19) & (.19) & $(.22)$ & $(.29)$ & $(.26)$ & $(.27)$ & $(.31)$ \\
\hline \multirow[t]{2}{*}{ Female } & $M$ & .44 & .49 & .56 & .56 & .57 & .38 & .48 & .53 \\
\hline & $S D$ & (.17) & (.17) & (.17) & (.16) & $(.26)$ & $(.32)$ & $(.32)$ & $(.28)$ \\
\hline \multicolumn{10}{|l|}{ Old } \\
\hline \multirow[t]{2}{*}{ Male } & $M$ & .33 & .37 & .48 & .44 & .25 & .31 & .50 & .18 \\
\hline & $S D$ & (.18) & (.14) & (.17) & $(.15)$ & (.18) & $(.24)$ & $(.17)$ & $(.30)$ \\
\hline \multirow[t]{2}{*}{ Female } & $M$ & .40 & .45 & .66 & .64 & .51 & .47 & .57 & .57 \\
\hline & $S D$ & $(.16)$ & $(.20)$ & $(.10)$ & $(.16)$ & $(.21)$ & $(.17)$ & $(.21)$ & $(.19)$ \\
\hline
\end{tabular}

$\mathrm{N}$, neutral; V, emotionally arousing. 
There was also a significant interaction between age and gender, $F(1,72)=7.60, M S E=.197, p<.01, \eta_{\mathrm{p}}^{2}=.10$, which reflected the lack of differences between young women and men $(M \mathrm{~s}=.54$ and .49 , respectively), $t(37)=0.85$, n.s., accompanied by large differences between older women and men, with the former performing significantly better $(M \mathrm{~s}=.53$ and .36 , respectively), $t(35)=3.02, p<.01$. This two-way interaction was qualified by a significant three-way interaction between age, gender, and test, $F(1,72)=4.10$, $M S E=.039, p<.05, \eta_{\mathrm{p}}{ }^{2}=.05$, which was similar to the one obtained in Experiment 1, such that the Age $\times$ Test interaction was significant for men $F(1,72)=5.20, p<.05$, but not for women, $F(1,72)=0.39$, n.s. (see Fig. 3). The latter finding was particularly true in the $\mathrm{V}-\mathrm{V}$ condition, as can be seen in Table 5.

Finally, as in Experiment 1, test and emotional arousal also interacted significantly, $F(3,216)=9.29, M S E=.025, p<.05$, $\eta_{\mathrm{p}}^{2}=.11$. As can be seen in Fig. 4, this interaction reflects different effects of emotional arousal on item and associative memory: Item memory benefited from emotional arousal, as the three types of pairs that involved emotionally arousing information $(\mathrm{N}-\mathrm{V}, \mathrm{V}-\mathrm{N}$, and $\mathrm{V}-\mathrm{V})$ were better recognized $(M=.52)$ than the pairs that did not include emotionally arousing information $(\mathrm{N}-\mathrm{N} ; M=.40), t(74)=4.77, p<01$. In contrast, using the same comparison, associative memory did not differ between the emotionally arousing $(M=.48)$ and nonarousing pairs $(M=.46), t(74)=0.34$, n.s. As in Experiment 1, these patterns were similar for young and older adults, reflected by the lack of a three-way interaction between age, test, and emotional arousal, $F(3,216)=1.54$, $M S E=.025$, n.s. The same patterns occurred when the two extreme conditions $(\mathrm{N}-\mathrm{N}$ and $\mathrm{V}-\mathrm{V})$ were compared. Item memory was higher in the $\mathrm{V}-\mathrm{V}$ condition $(M=.56)$ than in the N-N condition, $(M=.40), t(74)=4.43, p<.01$. In

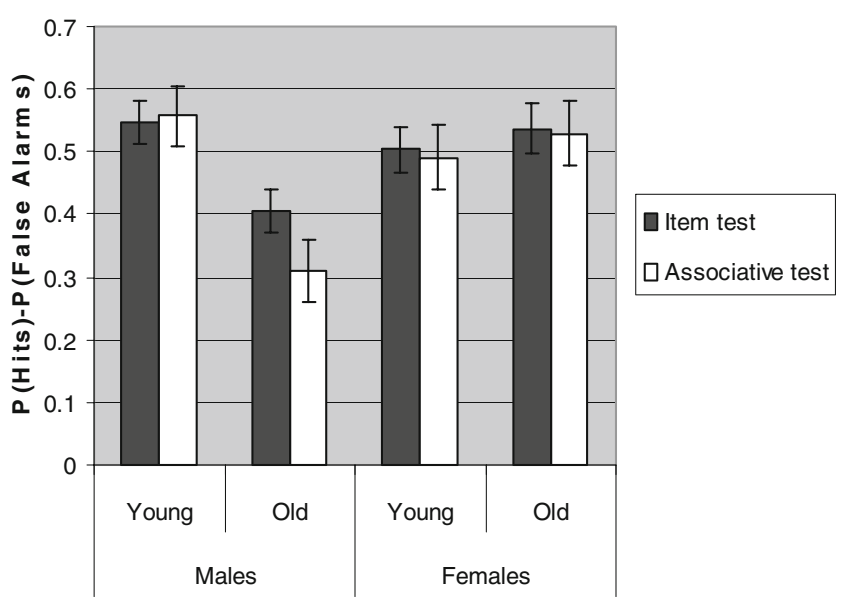

Fig. 3 Memory performance (mean proportions of hits minus proportions of false alarms) as a function of age group, gender, and test type (with standard errors) in Experiment 2

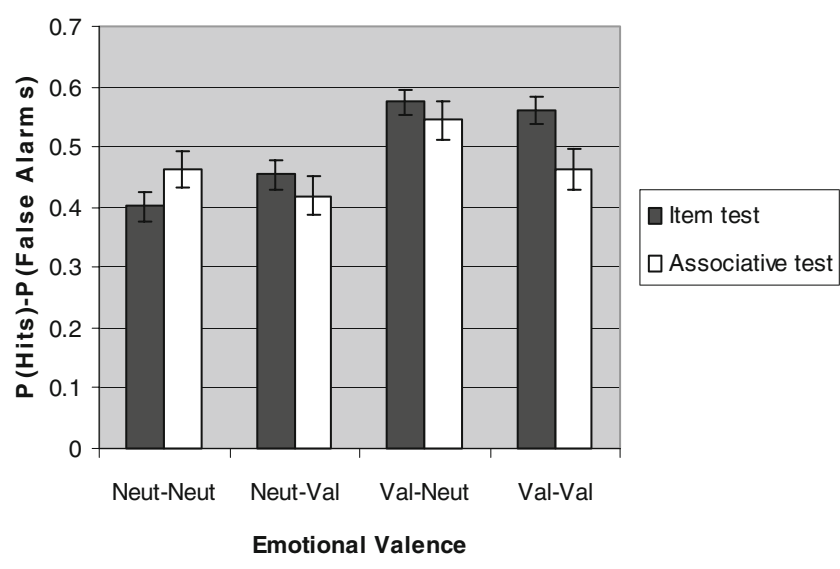

Fig. 4 Memory performance (mean proportions of hits minus proportions of false alarms) as a function of emotional arousal and test type (with standard errors) in Experiment 2

contrast, associative memory was not affected by emotional arousal $(M \mathrm{~s}=.46$ and .46 for $\mathrm{N}-\mathrm{N}$ and $\mathrm{V}-\mathrm{V}$, respectively), $t$ (74) $=0.39$, n.s. As in Experiment 1, these patterns were similar for young and older adults, as reflected in the nonsignificant interaction of age, test, and the two extreme emotional arousal conditions, $F(1,72)=2.74, M S E=.021$, n.s.

Separate proportions of hits and false alarms Table 6 shows proportions of hits and false alarms (with $S D$ s in parentheses) for the different combinations of conditions for younger and older adults. Appendix B presents the ANOVAs conducted for hits and false alarms, which were generally in line with the results for the hits-minus-false-alarms measure reported above.

\section{Discussion}

The results from Experiment 2 replicate and extend those obtained in Experiment 1. First, they show that the agerelated episodic memory differences between young and older adults are moderated by type of test and by gender. Specifically, they extend the evidence obtained in Experiment 1 showing that older men, in particular, show a differential decline in associative relative to item memory. One intriguing finding is that the Age $\times$ Test interaction was not significant, which suggests that our use of more easily integrated items (adjective-noun pairs) might have helped reduce the $\mathrm{AD}$ of older adults (see Badham, Estes, \& Maylor, 2011, for a similar finding).

The present study also manipulated emotional arousal. The results replicated those obtained in Experiment 1, showing a similar increase in item memory for emotionally arousing words for both younger and older adults. As in Experiment 1, the emotionally arousing words did not help memory for the adjective-noun associations in either age group. Such results do not support the claim that emotionally arousing words can help, via a deeper level of encoding, to 
Table 6 Mean proportions of hits (top) and false alarms (bottom; SDs in parentheses throughout table) for the different combinations of emotional arousal conditions and gender for the younger and older adults in Experiment 2

\begin{tabular}{|c|c|c|c|c|c|c|c|c|c|c|}
\hline & & & \multicolumn{4}{|l|}{ Item } & \multicolumn{4}{|c|}{ Associative } \\
\hline & & & $\mathrm{N}-\mathrm{N}$ & $\mathrm{N}-\mathrm{V}$ & $\mathrm{V}-\mathrm{N}$ & $\mathrm{V}-\mathrm{V}$ & $\mathrm{N}-\mathrm{N}$ & $\mathrm{N}-\mathrm{V}$ & $\mathrm{V}-\mathrm{N}$ & $\mathrm{V}-\mathrm{V}$ \\
\hline \multicolumn{11}{|l|}{ Hits } \\
\hline \multirow[t]{4}{*}{ Young } & Male & $M$ & .63 & .72 & .72 & .81 & .71 & .76 & .79 & .77 \\
\hline & & $S D$ & $(.18)$ & $(.14)$ & $(.14)$ & $(.14)$ & $(.23)$ & $(.18)$ & $(.18)$ & $(.18)$ \\
\hline & Female & $M$ & .59 & .66 & .70 & .75 & .64 & .64 & .70 & .76 \\
\hline & & $S D$ & $(.17)$ & $(.17)$ & (.13) & $(.13)$ & $(.21)$ & $(.17)$ & $(.17)$ & $(.21)$ \\
\hline \multirow[t]{4}{*}{ Older } & Male & $M$ & .63 & .70 & .73 & .73 & .67 & .77 & .76 & .64 \\
\hline & & $S D$ & $(.17)$ & $(.13)$ & (.13) & $(.13)$ & $(.22)$ & $(.17)$ & $(.17)$ & $(.22)$ \\
\hline & Female & $M$ & .59 & .69 & .78 & .83 & .77 & .84 & .80 & .90 \\
\hline & & $S D$ & $(.17)$ & $(.17)$ & (.13) & $(.13)$ & $(.21)$ & $(.17)$ & $(.17)$ & $(.21)$ \\
\hline \multicolumn{11}{|c|}{ False Alarms } \\
\hline \multirow[t]{4}{*}{ Young } & Male & $M$ & .20 & .20 & .17 & .20 & .19 & .27 & .19 & .19 \\
\hline & & $S D$ & $(.14)$ & $(.14)$ & (.09) & $(.14)$ & $(.18)$ & $(.23)$ & $(.18)$ & $(.23)$ \\
\hline & Female & $M$ & .17 & .22 & .13 & .18 & .13 & .29 & .18 & .24 \\
\hline & & $S D$ & (.13) & $(.13)$ & (.13) & (.13) & $(.17)$ & $(.21)$ & $(.21)$ & $(.21)$ \\
\hline \multirow[t]{4}{*}{ Older } & Male & $M$ & .30 & .33 & .23 & .31 & .31 & .46 & .30 & .49 \\
\hline & & $S D$ & (.13) & (.13) & (.13) & (.13) & (.17) & $(.22)$ & $(.17)$ & $(.22)$ \\
\hline & Female & $M$ & .20 & .22 & .15 & .21 & .25 & .38 & .25 & .31 \\
\hline & & $S D$ & (.13) & (.13) & (.13) & (.13) & $(.17)$ & $(.21)$ & $(.21)$ & $(.21)$ \\
\hline
\end{tabular}

$\mathrm{N}$, neutral; V, emotionally arousing.

create associations between these words, later leading to better memory of the associations.

It is interesting to note the large differences in the effects of the two emotionally arousing conditions that included one arousing and one neutral word (i.e., $\mathrm{V}-\mathrm{N}$ and $\mathrm{N}-\mathrm{V}$ ). Performance was significantly better in the condition that included an emotionally arousing adjective and a neutral noun than in the condition that included a neutral adjective and an emotionally arousing noun, and this was the case for both types of tests and for both younger and older adults. Apparently, memory for both the words in each pair and their association with each other was enhanced more with the use of an emotionally arousing adjective, even if the noun was neutral (happy-boy), than when the noun was emotionally arousing but the adjective was not (clear-death). According to the arousal-biased competition model (ABC model: Mather \& Sutherland, 2011), highly arousing items should enhance memory for the item and its intrinsic features. With respect to the interitem associations in the present study, it appears that a highly arousing item does not necessarily enhance memory for features that must be consciously bound to that item. This makes sense in consideration of the ABC model, which posits that processing will be enhanced for an arousing item at the cost of processing for the less-arousing item. However, when the feature (i.e., the adjective) is highly arousing, it appears that it is attributed to and subsequently associated with the less- arousing item (i.e., the noun) relatively easily and with reduced cost as compared with the $\mathrm{N}-\mathrm{V}$ condition.

\section{General discussion}

The purpose of the present experiments was to assess the potential moderating roles of emotional arousal and gender in the associative deficit among older adults.

With respect to emotional arousal and associative memory, the present study manipulated emotional arousal across word pairs, such that both words of each association were either emotionally arousing or neutral (Exp. 1) or the associations could consist of same-arousing or differently arousing stimuli (Exp. 2). The results from both experiments indicated an increase in item memory for positive and negative arousing words in both younger and older adults, which reflected increased hits for these items (see the appendices). The lack of a valence effect (i.e., no difference between positive and negative stimuli) is consistent with the previous finding of equivalent older-adult memory performance for positive and negative items when both categories were highly arousing (Kensinger, 2009b). Interestingly, in the present experiments, emotionally arousing words did not help either age group's memory for the associations between words within a pair (and even detracted somewhat in Experiment 1 
relative to item memory, due in part to increased false alarms, as reported in Appendix A). This finding extends previous research that examined young adults' recognition memory for emotionally arousing intact associations (Pierce \& Kensinger, 2011). Such a lack of effect of emotional arousal on associative memory may reflect the operation of opposing mechanisms that cancel each other out: On one hand, emotionally arousing words may lead to deeper levels of processing that may support the creation of better associations. On the other hand, emotionally arousing words may attract more attention than neutral words, leading to better memory of these words while hindering attention to (and, therefore, binding of) the relationships between them. Together, the operation of these two opposing mechanisms could in turn lead to no improvement (or even a slight decline, as happened in Exp. 1) in memory for the associations between emotionally arousing words, relative to neutral ones.

Although the use of integrated adjective-noun pairs in Experiment 2 failed to reduce the $\mathrm{AD}$ in older adult memory performance, it is important to note that we did not obtain the typical trade-off in emotional associative memory (e.g., Nashiro \& Mather, 2011), but instead, we obtained a pattern of results in which associations between neutral and emotionally arousing items were remembered equally well as neutral-neutral associations. The difference in results between our study and Nashiro and Mather's likely reflects differences in the types of stimuli used between the two experiments, such that our stimuli consisted of samevalence arousing pairs or adjective-noun pairs that were likely more easily integrated than Nashiro and Mather's stimuli (i.e., random shapes and pictures). Importantly, the role of the emotionally arousing item within the mixed-valence associations appears to influence this benefit so that performance was better when the emotionally arousing word served as the adjective rather than the noun (Exp. 2). This makes sense if the content of the emotionally arousing adjective carries forward to the neutral item, leading to relatively more elaborative processing of the association than when the adjective is neutral and the noun is arousing. One way of examining this possibility would be to experimentally manipulate encoding time or, alternatively, to provide participants control over encoding time. In this way, participants might improve performance in the $\mathrm{N}-\mathrm{V}$ condition when allowed sufficient time for fully integrating a neutral attribute and an emotionally arousing object. Furthermore, one might also expect a benefit for $\mathrm{V}-\mathrm{V}$ associations when participants could process each item independently and then elaborate on the association.

With respect to the potential moderating role of gender, females generally outperformed males in their memory performance (significantly so in Exp. 1). Such results converge with previous findings that have shown better performance for females in episodic memory tasks (Herlitz et al., 1999; Herlitz \& Yonker, 2002). Although this benefit was observed for both age groups, the benefit in memory performance for females over males was more consistently observed in the older adult sample. Previous studies testing age-related differences in item and associative memory did not look specifically at gender as a mediating factor. Interestingly, when we went back and analyzed the results of several of our previous studies on the AD (Naveh-Benjamin, 2000; Naveh-Benjamin et al., 2004), we did not see a systematic pattern of gender mediation, as we saw in the present study. One possibility is that such a mediating role was potentially related to the use of emotionally arousing stimuli in the present experiments. Although the four-way interaction in Experiment 2 was not significant, looking at Table 5, it can be noticed that the older male deficit in the associative test seems to be especially prominent in the condition in which both words were emotionally valenced, with this not being the case in females. Further research will establish whether this is a reliable phenomenon. Overall, although the present results indicate the lack of an agerelated $\mathrm{AD}$ in females, a more balanced view would be a relative rather than an absolute gender-mediated age-related deficit, with older males showing a relatively larger $\mathrm{AD}$ than older females. Furthermore, such a gender-mediated agerelated deficit was shown here in an experimental context in which valence-arousing stimuli were used, and future studied should assess its generalizability to other contexts.

Possible reasons for an AD showing up in males only should be investigated in further studies. One possibility is that the use of verbal materials in the present experiments could explain this differential decline in males' associative memory. Such a possibility would be in line with a metaanalysis conducted by Meinz and Salthouse (1998), which indicated that men showed larger age-related declines than did women in verbal episodic memory tasks. If the creation of verbal associations between the words in each pair is at least partially based on verbal abilities, it might be the case that older male participants, who show a larger decline in verbal abilities, might be especially poor in creating associations. In fact, some evidence has shown greater leftlateralized hippocampal activation in women than in men, and this increased activation corresponded with increased use of verbal encoding strategies by women as compared to men (Frings et al., 2006). Thus, it may be that women more spontaneously use encoding strategies for verbal material than do men, which results in increased activation in the regions responsible for memory. This is also in line with the more consistent gender effect observed in our older-adult group than in our younger-adult group, given past research that has suggested that older adults are less likely than young adults to spontaneously use encoding strategies (e.g., Dunlosky \& Hertzog, 2001; Naveh-Benjamin, Brav, \& Levy, 2007). Another possibility relates to differential age-related changes in brain structures. A structural MRI study by Raz et 
al. (2004) provided results that are consistent with the present results. This study assessed age- and gender-related differences in volumetric measurements of the cerebral cortex. The results indicated that men exhibited steeper age-related declines in the hippocampus than did women, and considering the fact that the hippocampus is implicated in the creation of associations (e.g., Henke, Weber, Kneifel, Wieser, \& Buck, 1999), this finding fits the larger AD shown by old males in the present experiments.

In conclusion, the present study has provided additional support for an associative-deficit hypothesis in older adults as one potential mechanism for their episodic memory decline, and has extended it to cases in which emotionally arousing stimuli are used. Emotionally arousing words supported an increase in item memory for both young and older adults, but in both age groups such emotionally arousing information did not increase (and slightly decreased in Exp. 1) memory for the associations between the words. However, the way in which emotionally arousing and neutral words combine and the processing induced by such combinations may indeed influence associative memory (i.e., the benefit of arousing-neutral associations over neutral-arousing and neutral-neutral associations in Exp. 2). Importantly, the results showed that gender may be a moderator in older adults' $\mathrm{AD}$, as older men, but not older women, showed a differential decline in associative over item memory performance.

Future studies could provide a replication of the present findings and further assess the potential mechanisms underlying the gender differences obtained. These studies could also further assess the effects of emotional arousal on agerelated differences in episodic memory for component items and their associations, as well as evaluate the role of changes in the allocation of attention to item and associative memory as a result of emotionally arousing information. Specifically, recent research has suggested that test forms may be differentially sensitive to distinctions between positive and negative materials (Zimmerman \& Kelley, 2010); thus, the present study could be replicated with cued or free recall testing to examine young and older adults' sensitivity to positive and negative associations. Additionally, given the gender differences observed in our older adult group, it would also be interesting to consider potential gender differences in metamemory and how gender differences may influence memory performance when monitoring and strategy selection are emphasized (e.g., value-directed remembering; Castel, 2008). Finally, given past research that has shown gender differences in functional brain connectivity when processing emotional faces (e.g., Mather, Lighthall, Nga, \& Gorlick, 2010), it might be the case that such gender differences in connectivity are important in processing emotional linguistic materials as well.
Author note This research was supported by a Department of Psychological Sciences Research Award (University of Missouri) to G.B.M. and P.J. Additionally, G.B.M. was supported by NIA Training Grant AG00030. The authors thank Thivia Mogan and the members of the Memory and Cognitive Aging Laboratory at the University of Missouri for their contributions to this study.

\section{Appendix A: Experiment 1}

Proportions of hits

Hit results are presented in Table 4 . The results of the fourway 2 (age) $\times 2$ (gender) $\times 2$ (test) $\times 3$ (emotional arousal) mixed-factor ANOVA revealed a marginally significant three-way interaction between age, test, and gender, $F(1$, 51) $=2.82, M S E=.028, p<.10, \eta_{\mathrm{p}}^{2}=.05$. Follow-up analyses for males revealed a marginally significant interaction between test and age, $F(1,51)=2.88, M S E=.028, p<$ .10 , such that young males performed similarly across item and association tests $(M \mathrm{~s}=.66$ and .70 , respectively) and older males performed better in the item test than the association test $(M \mathrm{~s}=.74$ and .67 , respectively). In contrast, older females showed performance similar to that of younger females in both the item $(M=.73)$ and association $(M=.70)$ tests, with no indication of an Age $\times$ Test interaction in this group, $F(1,51)=0.31$, $M S E=.028$, n.s.

In addition, test and emotional arousal also interacted significantly, $F(2,102)=3.40, M S E=.014, p<.05, \eta_{\mathrm{p}}{ }^{2}=$ .06. Pairwise comparisons revealed significantly higher performance in the item test for positive $(M=.76)$ and negative $(M=.74)$ arousing words as compared to neutral, nonarousing words $(M=.65)$, all $p$ s $<.05$. These comparisons also revealed no differences in the associative test for positive $(M=.69)$ and negative $(M=.72)$ arousing words as compared to neutral, nonarousing words $(M=.66), p>.1$. This interaction pattern was similar in younger and older adults (see Table 4).

\section{Proportions of false alarms}

False alarm results are also presented in Table 4 . The results of the four-way ANOVA indicated a marginally significant interaction of age and test, $F(1,51)=3.53, M S E=.013, p<.10$, $\eta_{\mathrm{p}}{ }^{2}=.06$. Follow-up comparisons indicated that, while there were no differences in the young groups' performance levels in the item and the associative tests $(M \mathrm{~s}=.15$ and .18 , respectively), $t(26)=1.49, p>.10$, older adults showed a higher level of false alarms in the associative than in the item tests ( $M \mathrm{~s}=.30$ and .22 , respectively), $t(25)=4.06, p<.05$.

In addition, test and emotional arousal also interacted significantly, $F(2,102)=4.42, M S E=.010, p<.05, \eta_{\mathrm{p}}{ }^{2}=$ .08. Pairwise comparisons revealed significantly higher 
false alarms in the associative test for positive $(M=.25)$ and negative $(M=.28)$ arousing words as compared to neutral, nonarousing words $(M=.19)$, all $p \mathrm{~s}<.05$. These comparisons also revealed no differences in false alarm rates in the item test for positive $(M=.21)$ and negative $(M=.18)$ arousing words as compared to neutral, nonarousing words $(M=.18), p>.1$. This interaction pattern was similar in younger and older adults (see Table 4 ).

\section{Appendix B: Experiment 2}

\section{Proportions of hits}

Hit results are presented in Table 6 . The results of the fourway analysis indicated a significant effect of emotional arousal, $F(3,216)=25.79, M S E=.016, p<.01, \eta_{\mathrm{p}}{ }^{2}=$ .26. Pairwise comparisons showed that the two combinations $\mathrm{V}-\mathrm{N}(M=.74)$ and $\mathrm{V}-\mathrm{V}(M=.77)$ were remembered significantly better than $\mathrm{N}-\mathrm{N}(M=.65)$ and $\mathrm{N}-\mathrm{V}(M=.72)$, $p<.01$. Likewise, comparison of the two extreme conditions $(\mathrm{N}-\mathrm{N}$ vs. $\mathrm{V}-\mathrm{V})$ showed overall better performance for the emotionally arousing adjective-noun pairs $(M=.77)$ than for the neutral adjective-noun pairs $(M=.65), p<$ .01 . The comparison of the two mixed-valence conditions $(\mathrm{N}-$ $\mathrm{V}$ and $\mathrm{V}-\mathrm{N})$ showed no differences between the two $(M \mathrm{~s}=.75$ and .72 for $\mathrm{V}-\mathrm{N}$ and $\mathrm{N}-\mathrm{V}$, respectively), n.s. This pattern was similar for both tests.

There was also a significant interaction of age and gender, $F(1,72)=4.67, M S E=.131, p<.05, \eta_{\mathrm{p}}{ }^{2}=.06$, which reflected no differences in performance between young men and women $(M \mathrm{~s}=.74$ and .68 , respectively), $t(37)=1.37$, n.s., accompanied by large differences between older women and men, with the former performing marginally significantly better ( $M \mathrm{~s}=.78$ and .70 , respectively), $t(35)=1.68, p<.10$. This two-way interaction was qualified by a significant threeway interaction between age, gender, and test, $F(1,72)=5.41$, $M S E=.026, p<.05, \eta_{\mathrm{p}}{ }^{2}=.07$, which was similar to the one obtained in Experiment 1.

Finally, as in Experiment 1, test and emotional arousal also interacted significantly, $F(3,216)=5.91, M S E=.014, p<.05$, $\eta_{\mathrm{p}}{ }^{2}=.08$. As can be seen in Table 6, this interaction reflects different effects of emotional arousal on item and associative memory: Item memory benefited from emotional arousal, as the three types of pairs that involved emotionally arousing information $(\mathrm{N}-\mathrm{V}, \mathrm{V}-\mathrm{N}$, and $\mathrm{V}-\mathrm{V})$ were better recognized $(M=.73)$ than the pairs that did not include emotionally arousing information $(\mathrm{N}-\mathrm{N}$, $M=.60), p<.01$. In contrast, using the same comparison, associative memory did not differ between the emotionally arousing $(M=.75)$ and nonarousing pairs $(M=.70)$, n.s. As in Experiment 1, these patterns were similar for young and older adults, reflected by the lack of a three-way interaction between age, test, and emotional arousal, $F(3,216)=1.70, M S E=.014$, n.s. The same patterns occurred when the two extreme conditions $(\mathrm{N}-\mathrm{N}$ and $\mathrm{V}-\mathrm{V})$ were compared. Item memory was higher in the $\mathrm{V}-\mathrm{V}$ condition $(M=.77)$ than in the $\mathrm{N}-\mathrm{N}$ condition $(M=.60), p<.01$. In contrast, associative memory was not affected by emotional arousal $(M \mathrm{~s}=.70$ and .75 for $\mathrm{N}-\mathrm{N}$ and $\mathrm{V}-\mathrm{V}$, respectively), n.s. As in Experiment 1, these patterns were similar for younger and older adults, as reflected in the follow-up interaction of age, test, and the two extreme emotional arousal conditions, which showed the lack of a triple interaction, $F(1,72)=0.97$, $M S E=.013$, n.s.

\section{Proportions of false alarms}

False alarm results are also presented in Table 6 . The results of the four-way analysis indicated a significant effect of emotional arousal, $F(3,216)=20.26, M S E=.015, p<.01, \eta_{\mathrm{p}}{ }^{2}=.22$. Follow-up pairwise comparisons showed that the two combinations $\mathrm{N}-\mathrm{V}(M=.30)$ and $\mathrm{V}-\mathrm{V}(M=.26)$ resulted in higher false alarm rates than did $\mathrm{N}-\mathrm{N}(M=.22)$ and $\mathrm{V}-$ $\mathrm{N}(M=.20), p<.05$. A comparison of the two extreme conditions (N-N vs. V-V) showed no difference in false alarms between the emotionally arousing adjective-noun pairs $(M=.26)$ and the neutral adjective-noun pairs $(M=$ $.22), p<.05$. The comparison of the two mixed-valence conditions ( $\mathrm{N}-\mathrm{V}$ and $\mathrm{V}-\mathrm{N})$ showed significantly smaller false alarm rates in the $\mathrm{V}-\mathrm{N}(M=.20)$ than in the $\mathrm{N}-\mathrm{V}(M=.30)$ condition, $p<.05$. This pattern was similar for both tests.

There was also a significant interaction of age and test, $F(1,72)=6.15, M S E=.032, p<.05, \eta_{\mathrm{p}}{ }^{2}=.08$, reflecting no differences in false alarms on the item and associative tests for younger adults $(M \mathrm{~s}=.18$ and .21 , respectively), $t(37)=$ 1.32 , n.s., but higher rates in the associative than in the item test in older adults $(M \mathrm{~s}=.35$ and .25 , respectively), $t(35)=$ $4.75, p<.01$.

Finally, as in Experiment 1, test and emotional arousal also interacted significantly, $F(3,216)=5.86, M S E=.012, p<.05$, $\eta_{\mathrm{p}}{ }^{2}=.08$. As can be seen in Table 6 , This interaction reflects different effects of emotional arousal on item and associative memory: Item memory false alarms were not affected by emotional arousal, as the three types of pairs that involved emotionally arousing information $(\mathrm{N}-\mathrm{V}, \mathrm{V}-\mathrm{N}$, and $\mathrm{V}-\mathrm{V})$ resulted in false alarm rates $(M=.22)$ similar to that for pairs that did not include emotionally arousing information $(\mathrm{N}-\mathrm{N}$, $M=.21)$, n.s. However, false alarms for the associative test were higher in the emotionally arousing $(M=.30)$ than in the emotionally nonarousing $(M=.22)$ pairs, $p<.01$. As in Experiment 1, these patterns were similar for younger and older adults, reflected by the lack of a three-way interaction between age, test, and emotional arousal, $F(3,216)=0.78, M S E=.012$, n.s. The same patterns occurred when the two extreme conditions $(\mathrm{N}-\mathrm{N}$ and $\mathrm{V}-\mathrm{V})$ were compared. False alarm rates for 
item memory were similar in the $\mathrm{V}-\mathrm{V}(M=.21)$ and the $\mathrm{N}-\mathrm{N}$ $(M=.21)$ conditions, n.s. In contrast, false alarm rates for associative memory were higher in the emotionally arousing $\mathrm{V}-\mathrm{V}$ condition $(M=.30)$ than in the neutral $\mathrm{N}-\mathrm{N}$ condition $(M=.22), p<.01$. As in Experiment 1 , these patterns were similar for young and older adults, as reflected in the follow-up interaction of age, test, and the two extreme emotional arousal conditions, which showed the lack of a triple interaction, $F(1,72)=1.82, M S E=.01$, n.s.

\section{References}

Badham, S. P., Estes, Z., \& Maylor, E. A. (2011, May 30). Integrative and semantic relations equally alleviate age-related associative memory deficits. Psychology and Aging. doi:10.1037/a0023924

Balota, D. A., Yap, M. J., Cortese, M. J., Hutchison, K. A., Kessler, B., Loftis, B., \& Treiman, R. (2007). The English Lexicon Project. Behavior Research Methods, 39, 445-459. doi:10.3758/ BF03193014

Bastin, C., \& Van der Linden, M. (2006). The effects of aging on the recognition of different types of associations. Experimental Aging Research, 32, 61-77.

Bradley, M. M., \& Lang, P. J. (1999). Affective norms for English words (ANEW): Stimuli, instruction manual and affective ratings (Tech. Rep. C-1). In Center for Research in Psychophysiology. Gainesville, FL: University of Florida.

Cahill, L., Haier, R. J., White, N. S., Fallon, J., Kilpatrick, L., Lawrence, C., \& Alkire, M. T. (2001). Sex-related differences in amygdala activity during emotionally influenced memory storage. Neurobiology of Learning and Memory, 75, 1-9. doi:10.1006/nlme.2000.3999

Cahill, L., Uncapher, M., Kilpatrick, L., Alkire, M. T., \& Turner, J. (2004). Sex-related hemispheric lateralization of amygdala function in emotionally influenced memory: An fMRI investigation. Learning and Memory, 11, 261-266. doi:10.1101/1m.70504

Canli, T., Desmond, J. E., Zhao, Z., \& Gabrieli, J. D. E. (2002). Sex differences in the neural basis of emotional memories. Proceedings of the National Academy of Sciences, 99, 10789-10794. doi:10.1073/pnas.162356599

Carstensen, L. L., Fung, H. H., \& Charles, S. T. (2003). Socioemotional selectivity theory and the role of emotion in the second half of life. Motivation and Emotion, 27, 103-123.

Castel, A. D. (2005). Memory for grocery prices in younger and older adults: The role of schematic support. Psychology and Aging, 20, $718-721$.

Castel, A. D. (2008). The adaptive and strategic use of memory by older adults: Evaluating processing and value-directed remembering. In A. S. Benjamin \& B. H. Ross (Eds.), The psychology of learning and motivation (Vol. 48, pp. 225-270). San Diego, CA: Academic Press.

Castel, A. D., \& Craik, F. I. M. (2003). The effects of aging and divided attention on memory for item and associative information. Psychology and Aging, 18, 873-885.

Chalfonte, B. L., \& Johnson, M. K. (1996). Feature memory and binding in young and older adults. Memory and Cognition, 24, 403-416. doi:10.3758/BF03200930

Charles, S. T., Mather, M., \& Carstensen, L. L. (2003). Aging and emotional memory: The forgettable nature of negative images for older adults. Journal of Experimental Psychology: General, 132, 310-324.

Craik, F. I. M. (1983). On the transfer of information from temporary to permanent memory. Philosophical Transactions of the Royal Society $B, 302,341-359$.
Craik, F. I. M. (1986). A functional account of age differences in memory. In F. Klix \& H. Hagendorf (Eds.), Human memory and cognitive capabilities, mechanisms, and performance (pp. 409 422). Amsterdam: North-Holland and Elsevier.

Doerksen, S., \& Shimamura, A. P. (2001). Source memory enhancement for emotional words. Emotion, 1, 5-11.

Dunlosky, J., \& Hertzog, C. (2001). Measuring strategy production during associative learning: The relative utility of concurrent versus retrospective reports. Memory and Cognition, 29, 247253. doi:10.3758/BF03194918

Easterbrook, J. A. (1959). The effect of emotion on cue utilization and the organization of behavior. Psychological Review, 66, 183-201.

Frings, L., Wagner, K., Unterrainer, J., Spreer, J., Halsband, U., \& SchulzeBonhage, A. (2006). Gender-related differences in lateralization of hippocampal activation and cognitive strategy. NeuroReport, 17, 417-421.

Hamann, S. (2001). Cognitive and neural mechanisms of emotional memory. Trends in Cognitive Sciences, 5, 394-400.

Hamann, S., \& Canli, T. (2004). Individual differences in emotion processing. Current Opinion in Neurobiology, 14, 233-238.

Hasher, L., \& Zacks, R. T. (1988). Working memory, comprehension, and aging: A review and a new view. In G. H. Bower (Ed.), The psychology of learning and motivation: Advances in research and theory (Vol. 22, pp. 193-225). San Diego, CA: Academic Press. doi:10.1016/S0079-7421(08)60041-9

Henke, K., Weber, B., Kneifel, S., Wieser, H. G., \& Buck, A. (1999). Human hippocampus associates information in memory. Proceedings of the National Academy of Sciences, 96, 5884-5889.

Herlitz, A., Airaksinen, E., \& Nordstrom, E. (1999). Sex differences in episodic memory: The impact of verbal and visuospatial ability. Neuropsychology, 13, 590-597.

Herlitz, A., Nilsson, L.-G., \& Backman, L. (1997). Gender differences in episodic memory. Memory and Cognition, 26, 801-811.

Herlitz, A., \& Rehnman, J. (2008). Sex differences in episodic memory. Current Directions in Psychological Science, 17, 52-56.

Herlitz, A., \& Yonker, J. E. (2002). Sex differences in episodic memory: The influence of intelligence. Journal of Clinical and Experimental Neuropsychology, 24, 107-114.

Kensinger, E. A. (2009a). Emotional memory across the adult lifespan. New York: Psychology Press.

Kensinger, E. A. (2009b). How emotion affects older adults' memories for event details. Memory, 17, 208-219. doi:10.1080/ 09658210802221425

Kensinger, E. A., Garoff-Eaton, R. J., \& Schacter, D. L. (2007a). Effects of emotion on memory specificity: Memory trade-offs elicited by negative visually arousing stimuli. Journal of Memory and Language, 56, 575-591. doi:10.1016/j.jml.2006.05.004

Kensinger, E. A., Gutchess, A. H., \& Schacter, D. L. (2007b). Effects of aging and encoding instructions on emotion-induced memory trade-offs. Psychology and Aging, 22, 781-795. doi:10.1037/ 0882-7974.22.4.781

Kensinger, E. A., O’Brien, J. L., Swanberg, K., Garoff-Eaton, R. J., \& Schacter, D. L. (2007c). The effects of emotional content on reality-monitoring performance in young and older adults. Psychology and Aging, 22, 752-764. doi:10.1037/ 0882-7974.22.4.752

Lacreuse, A., Kim, C. B., Rosene, D. L., Killiany, R. J., Moss, M. B., Moore, T. L., \& Herndon, J. G. (2005). Sex, age, and training modulate spatial memory in the rhesus monkey (Macaca mulatta). Behavioral Neuroscience, 119, 118-126.

Lewin, C., Wolgers, G., \& Herlitz, A. (2001). Sex differences favoring women in verbal but not in visuospatial episodic memory. Neuropsychology, 15, 165-173.

Light, L. L. (1991). Memory and aging: Four hypotheses in search of data. Annual Review of Psychology, 42, 333-376. doi:10.1146/ annurev.ps.42.020191.002001 
Light, L. L., Patterson, M. M., Chung, C., \& Healy, M. R. (2004). Effects of repetition and response deadline on associative recognition in young and older adults. Memory and Cognition, 32, 1182-1193.

Mandler, G. (1975). Mind and emotion. New York, NY: Wiley.

Mather, M. (2007). Emotional arousal and memory binding: An objectbased framework. Perspectives on Psychological Science, 2, 3352. doi:10.1111/j.1745-6916.2007.00028.x

Mather, M., \& Carstensen, L. L. (2005). Aging and motivated cognition: The positivity effect in attention and memory. Trends in Cognitive Sciences, 9, 496-502.

Mather, M., Lighthall, N. R., Nga, L., \& Gorlick, M. A. (2010). Sex differences in how stress affects brain activity during face viewing. NeuroReport, 21, 933-937.

Mather, M., Mitchell, K. J., Raye, C. L., Novak, D. L., Greene, E. J., \& Johnson, M. K. (2006). Emotional arousal can impair feature binding in working memory. Journal of Cognitive Neuroscience, 18, 614-625. doi:10.1162/jocn.2006.18.4.614

Mather, M., \& Nesmith, K. (2008). Arousal-enhanced location memory for pictures. Journal of Memory and Language, 58, 449-464. doi:10.1016/j.jml.2007.01.004

Mather, M., \& Sutherland, M. R. (2011). Arousal-biased competition in perception and memory. Perspectives on Psychological Science, 6, 114-133. doi:10.1177/1745691611400234

Maylor, E. A., Reimers, S., Choi, J., Collaer, M. L., Peters, M., \& Silverman, I. (2007). Gender and sexual orientation differences in cognition across adulthood: Age is kinder to women than to men regardless of sexual orientation. Archives of Sexual Behavior, 36, 235-249.

Meinz, E. J., \& Salthouse, T. A. (1998). Is age kinder to females than to males? Psychonomic Bulletin \& Review, 5, 56-70. doi:10.3758/ BF03209457

Mikels, J. A., Larkin, G. R., Reuter-Lorenz, P. A., \& Carstensen, L. L. (2005). Divergent trajectories in the aging mind: Changes in working memory for affective versus visual information with age. Psychology and Aging, 20, 542-553.

Nashiro, K., \& Mather, M. (2011). How arousal affects younger and older adults' memory binding. Experimental Aging Research, 37, 108-128. doi:10.1080/0361073X.2011.536746

Naveh-Benjamin, M. (2000). Adult-age differences in memory performance: Tests of an associative deficit hypothesis. Journal of
Experimental Psychology. Learning, Memory, and Cognition, $26,1170-1187$.

Naveh-Benjamin, M., Brav, T. K., \& Levy, O. (2007). The associative memory deficit of older adults: The role of strategy utilization. Psychology and Aging, 22, 202-208. doi:10.1037/08827974.22.1.202

Naveh-Benjamin, M., Guez, J., Kilb, A., \& Reedy, S. (2004). The associative memory deficit of older adults: Further support using face-name associations. Psychology and Aging, 19, 541-546. doi:10.1037/0882-7974.19.3.541

Naveh-Benjamin, M., Hussain, Z., Guez, J., \& Bar-On, M. (2003). Adult age differences in episodic memory: Further support for an associative-deficit hypothesis. Journal of Experimental Psychology. Learning, Memory, and Cognition, 29, 826-837. doi:10.1037/02787393.29.5.826

Old, S. R., \& Naveh-Benjamin, M. (2008a). Differential effects of age on item and associative measures of memory: A meta-analysis. Psychology and Aging, 23, 104-118. doi:10.1037/08827974.23.1.104

Old, S., \& Naveh-Benjamin, M. (2008b). Memory for people and their actions: Further evidence for an age-related associative deficit. Psychology and Aging, 23, 467-472. doi:10.1037/ 0882-7974.23.2.467

Pierce, B. H., \& Kensinger, E. A. (2011). Effects of emotion on associative recognition: Valence and retention interval matter. Emotion, 11, 139-144.

Raz, N., Gunning-Dixon, F., Head, D., Rodrigue, K. M., Williamson, A., \& Acker, J. D. (2004). Aging, sexual dimorphism, and hemispheric asymmetry of the cerebral cortex: Replicability of regional differences in volume. Neurobiology of Aging, 25, 377-396.

Salthouse, T. A. (1996). The processing-speed theory of adult age differences in cognition. Psychological Review, 103, 403-428. doi: 10.1037/0033-295X.103.3.403

Toglia, M. P., \& Battig, W. F. (1978). Handbook of semantic word norms. Hillsdale, NJ: Erlbaum.

Zimmerman, C. A., \& Kelley, C. M. (2010). "I'll remember this!" Effects of emotionality on memory predictions versus memory performance. Journal of Memory and Language, 62, 240-253. doi:10.1016/j.jml.2009.11.004 